\title{
Resolution and application of electromagnetic induction heating technology
}

\author{
Haiwei $\mathrm{Xu}^{1, \mathrm{a}}$, Jiangping $\mathrm{CaO}^{2, \mathrm{~b}}$, Gang $\mathrm{Li}^{3, \mathrm{c}}$, Yonggang $\mathrm{Wu}^{4, \mathrm{~d}}$ \\ Comment: All of the authors are in Chinese \\ ${ }^{1}$ Sichuan Zhongceliangyikeji CO., LTD, Chengdu Sichuan province, China \\ ${ }^{2}$ Sichuan Zhongceliangyikeji CO., LTD, Chengdu Sichuan province, China \\ ${ }^{3}$ Sichuan Zhongceliangyikeji CO., LTD, Chengdu Sichuan province, China \\ ${ }^{4}$ Sichuan Zhongceliangyikeji CO., LTD, Chengdu Sichuan province, China \\ bemail:2479860633@qq.com
}

Keywords: Electromagnetic, Induction, Heat source

\begin{abstract}
This paper shows electromagnetic induction heating technology advantages and great potential application as a new heat source, which is based on the principle of electromagnetic induction heating technology, application methods and application fields, and combined with comparative analysis of the test. The electromagnetic induction heating technology will replace traditional heat sources in many ways for its unique advantages, upgrade and change the electric heating technology.
\end{abstract}

The induction heating bases on the electromagnetic induction discovered by Michael Faraday in 1831, Then Foucault and Heaviside put forward the theory on eddy current and induction heating. The energy saving effect of electromagnetic heating is more remarkable than traditional heating methods, it saves between 30 and 50 percent average wattage, and it also has many relative advantages, such as heat stableness, rapid heating, long service life, convenient maintenance, etc. So it is usually used for the energy saving projects across many industries such as plastic rubber products, chemical engineering, medicine, foodstuff, energy, printing and constructional profiles, and so on. For instance, the heating of plastic-wire drawing, blowing, prilling and shooting. Cable production extruder heating, plastic extruding machine, thermoplastic plastic pipes, profile production. Heat tracing pipeline, thermostatically controlled warming, etc.

\section{Traditional heat source}

We require heating equipment in many industry, the traditional heat sources are given priority with coal, gas, resistance wire, etc. There are five shortcomings to get heat by the form of burning fuel such as coal, oil and gas. Low efficiency and high energy consumption: A part of fuel burning heat absorbed by the boiler, and the rest send out into the air. Big environmental temperature rising: environmental temperature goes up greatly because of the heat loss, it is great influence on production environment in summer especially. Some companies have to reduce temperature with air-condition, this also causes secondary waste of energy. Low thermal conductivity: The thermal conductivity of speed and efficiency is slow and controlled difficultly, inevitable thermal inertia, because this determined by the material of the boiler thermal conductivity. Fuel storage problem: we should have special fuel storage space and security. Environmental pollution problems: Fuel combustion emissions and waste residue caused serious environmental pollution.

The resistance wire heating method is developed in recent decades, and has some advantages compared with burning fuel mode. They are more accurate temperature control, less environmental pollution and without considering fuel storage, etc. It has replaced fuel combustion heat sources in many industries and equipment. However, it doesn't develop and apply generally because it also has some disadvantages. High heat loss: Existing enterprises adopt the heating mode, which is winded by resistance wire, heat double-side (the circle of inside and outside), the inside (close to the cylinder part) 
of heat transfer into the cylinder, most of the outside heat lost to the air, and result electric energy waste. The environmental temperature rises for a large number of heating lost, the ambient temperature has a great influence on production environment especially in summer, the working temperature is usually more than 45 Celsius, some enterprises have to reduce temperature by air-condition, it causes secondary waste of energy. A short service life and a large amount of maintenance: because of using resistance wire heating, the heating temperature will be up to about 300 Celsius, the resistance wire is easy to burn out for high temperature aging, the service life of common electric heating circle is about half a year. So the maintenance workload is really larger.

\section{Electromagnetic induction heating}

The principle of electromagnetic heating is that $50 \mathrm{hz}$ alternating current(AC) transforms into direct current(DC) by internal rectification filter circuit, and then DC changes into 20-30Khz high frequency and voltage, current by Pulse-Width Modulation(PWM) control circuit, The high speed change of current produces changing magnetic field through coil, it was generating a myriad of small eddy current inside heated metal to high fever, when magnetic field lines in magnetic field went through the heated metal objects.

Many flat heating experiment of electromagnetic heating did test, the data rates were nearly the same. For example: The test are obtained from $5 \mathrm{~mm}$ thick carbon steel by real-time monitoring in a given situation of 22 Celsius, $17 \mathrm{khz}$ coil frequency and $15-20 \mathrm{~m}$ from steel plate( Q235A). The test data is shown in table 1 .

\begin{tabular}{|c|c|c|c|c|c|}
\hline NO. & Test time & Aver Tem $\left({ }^{\circ} \mathrm{C}\right)$ & $\operatorname{Max} \operatorname{Tem}\left({ }^{\circ} \mathrm{C}\right)$ & Elec meter $(\mathrm{kw} \cdot \mathrm{h})$ & Test current(A) \\
\hline 1 & $14: 35$ & 22 & 22 & 265.4 & $8.42 / 8.11 / 8.62$ \\
\hline 2 & $14: 36$ & 66 & 98 & & $7.31 / 7.22 / 7.64$ \\
\hline 3 & $14: 37$ & 128 & 160 & & $7.06 / 7.12 / 7.41$ \\
\hline 4 & $14: 38$ & 158 & 272 & & $6.89 / 6.91 / 7.25$ \\
\hline 5 & $14: 40$ & 205 & 319 & & $6.53 / 6.65 / 7.03$ \\
\hline 6 & $14: 43$ & 211 & 409 & & $6.27 / 6.42 / 6.65$ \\
\hline 7 & $14: 44$ & 248 & 424 & & $6.11 / 6.18 / 6.41$ \\
\hline 8 & $14: 46$ & 278 & 463 & & $5.96 / 6.02 / 6.25$ \\
\hline 9 & $14: 49$ & 297 & 493 & & $5.91 / 5.96 / 6.27$ \\
\hline 10 & $14: 51$ & 304 & 496 & & $5.77 / 5.71 / 6.24$ \\
\hline 11 & $14: 53$ & 314 & 497 & & $5.64 / 5.58 / 6.29$ \\
\hline 12 & $14: 55$ & 315 & 495 & & $5.59 / 5.60 / 6.23$ \\
\hline 13 & $15: 00$ & 322 & 495 & & $5.57 / 5.63 / 6.28$ \\
\hline
\end{tabular}

Table 1: Heating plate test

To summarize of these experiments, there are many advantages of electromagnetic induction heating method, such as rapid warming, high thermal efficiency, no open flame, no smoke and no harmful gases, no heat radiation for surrounding, it also has a small volume and good security. The individual analysis is following:

More energy efficient: The thermischer of electromagnetic induction heating is usually more than 80 percent, Traditional heat resources' is between 40 and 65 percent, so the former is more energy efficient than the latter nearly one times. The metal appliances are heating rapidly when they accept magnetic field induced current. Because they have electrical and thermal conductivity (iron, stainless steel and enamel), their material molecules move a high speed irregularly, and their collision and friction generate thermal radiation each other.

Better security : It's safe to human body that the frequency of electromagnetic oscillation is only between 20 and $30 \mathrm{Khz}$. 
Better environmental protection, No substance is released during the heating process of magnetic field induction.

More accurate on temperature control: The microcomputer is used to control electromagnetic heating temperature and automatically deploy an appropriate temperature for needs conveniently and accurately.

Long service life: Don't need to change heating ring because of its lasting about 100 Celsius. It reduces secondary input which compared to resistance wire heating method.

Easier installation: Only require simple support.

Higher output: Improve output because of high heating efficiency and short heating-up time.

\section{Pay attention to the problem of induction heating}

To make full use of many of the advantages of induction heating, we need to pay close attention to some problems on its structure and control system design and implementation.

First: Choose electricity frequency exactly;

Second: Enhance conductor's end voltage;

Next: Choose induction ring's electricity density accurately;

Next: Choose good, heat-resisting and thermal baffle materials;

Last: Take full advantage of the conductor's cooling water.

The other feasible applications of electromagnetic heating technology (developed able industries and equipment)

The electromagnetic heating advantages have been applied and developed into many industries, such as rubber production, pharmaceutical and chemical, energy, food, building materials, printing equipment, and tobacco etc. their theory principles are comfortable in the same function, for instance, they have universality on drying device between food and pharmaceutical industry. So we only need to analyses the key structure of different devices, and modify energy research of present heating equipment, while we popularize this technology to other fields.

Rattler-drying machines or drum ovens

Feasibility analysis: Rattler-drying machines is a little different from a water-removing cylinder machine of its function and structure, Most of them heat by burning coal and resistance, some of them heat by infrared technology. The electromagnetic heating is super to another heating ways on saving effect. It also will be fixed sample and doesn't need burner, its overall structure is simple. Heating device which is made into circle or oval shape by heat-resistant cable can be mounted at the cylinder's or rotary furnace's outside, and set aside a certain distance. It is covered by an insulation structure or body with dehydrating units and feeder-discharge units. Drum ovens work alone and together with others in assembly line.

This equipment is suitable for many kinds of fields such as drying operation of food, pharmaceutical and mine industries etc. We only adjust its structure and heating temperature with the same rationale.

Conveyors and feeding machines with drying and curing effect

Feasibility analysis: There are mesh-belt conveyers and raddle conveyors in this type of equipment which transport materials with heating to dry and bake. The electromagnetic heating heat at iron or steel plate with good thermal conductance or convey or with great magnetic permeability. In the case of materials can be directly baked, its advantage is more remarkable than the present equipment with burning coal, gas and resistance wire. But, it doesn't work in the other way.

The heating device can be fixed between conveyer belt and roller which is under conveyer belt, it is parallel to conveyer belt for keeping a certain distance. Once the equipment work, the materials on conveyer belt will be dried or baked, and we can control baking temperature by commanding the frequency of the electric current and power of induction coil.

The equipment can be used in baking food, medicine and paper industries, drying, etc. 
Industrial heaters

Feasibility analysis: It is easy to control the local heating temperature and conducive to the realization of plastic molding process that use electromagnetic heating mode. For example, electromagnetic heating can replace the present heat sources of die-casting molding heater. In theory, the improved heater's structure can be more simplified. However, we carried it out difficultly, because the equipment based on traditional plastic molding equipment, we should know and understand its principle and structure enough, and understand something of plastic molding process.

Industrial heater can be used for plastic and rubber molding equipment, etc.

An electric heating plate

Feasibility analysis: Electric heating plate which equipped with a lot of equipment for heating work-piece, material or equipment, can be directly placed at the outside of heated object according to needs, it is easy to use. It is designed a flat structure with resistance wire and infrared tube covered outer insulation device. The applicability of heating plate is really extensive, the user can choose different specifications and place where need to be heated according to their own needs.

The electric heating plate can be made of electromagnetic, flat coils are placed its inside. The magnetic field shielding devices are installed at bottom and sides. The heating plate can be designed direct heating and indirect heating. The heating plate can be set above a ceramic glass plate, Magnetic induction line heat the permeable material (steel or iron, etc.) at $25 \mathrm{~mm}$ distance through this layer of glass directly; On the other way, The heating plate can be set above a metal plate, induction coil heat metal plate, metal plate will be heated and then its quantity of heat radiate outward to heat the other material.

The electric heating plate can be used for textile and printing and dyeing industries, etc.

\section{Conclusions}

The electromagnetic heating is attended and known as a new energy by human more and more, and has started to replace traditional heat sources. The study has a huge area of electromagnetic induction, heat conduction, electromagnetic shield and their relative control systems. You must study deeply and test repeatedly to get and apply it expertly. It is really better than traditional heat sources in many ways, saving effect and losing reduction is remarkable especially. To summarize, electromagnetic heating application outlook is pretty vast in many kinds of industries and fields, it will replace traditional heat sources progressively.

\section{References}

[1] Gong Qin, Zhao Li, Journal of Jianghan University (Natural Science Version), 34 (1) (2006), (In Chinese)

[2] Xibin Liu, Wenhua Luo, Journal of Yueyang Normal University (Natural Science Version), 15 (1): 31-33 (2002), (In Chinese)

[3] Zhichuan Tian, Journal Tonghua Normal University, 25 (4):44-45 (2004), (In Chinese).

[4] Suohong Guo. Electrodynamics [M].Version 2. Beijing Higher Education Press (1997), (In Chinese)

[5] Canbin Liang, Guangrong Qin and Zhujian Liang, Electromagnetism [M]. Version 2. Beijing Higher Education Press, ( 2004), (In Chinese)

[6] Defu Wan, Shixiang Luo. Magnetic physics [M]. Beijing Electronic Industry Press (1985), (In Chinese)

[7] Shouting Jiang. Ferromagnetic theory [M].Beijing Science Press (1993), (In Chinese) 